This item was submitted to Loughborough's Research Repository by the author.

Items in Figshare are protected by copyright, with all rights reserved, unless otherwise indicated.

\title{
Overcoming 'crisis': Mobility capabilities and 'stretching' a migrant identity among young Irish in London and return migrants
}

\section{PLEASE CITE THE PUBLISHED VERSION}

https://doi.org/10.1111/imig.12577

\section{PUBLISHER}

Wiley

\section{VERSION}

AM (Accepted Manuscript)

\section{PUBLISHER STATEMENT}

This is the peer reviewed version of the following article: Overcoming 'crisis': Mobility capabilities and 'stretching' a migrant identity among young Irish in London and return migrants. International Migration, 58 (1), pp.31-44, which has been published in final form at https://doi.org/10.1111/imig.12577. This article may be used for non-commercial purposes in accordance with Wiley Terms and Conditions for Use of Self-Archived Versions.

\section{LICENCE}

CC BY-NC-ND 4.0

\section{REPOSITORY RECORD}

Lulle, Aija, Liam Coakley, and Piaras MacEinri. 2019. “Overcoming 'crisis': Mobility Capabilities and 'stretching' a Migrant Identity Among Young Irish in London and Return Migrants". figshare. https://hdl.handle.net/2134/37154. 


\title{
Overcoming 'Crisis': Mobility Capabilities and 'stretching' a Migrant Identity Among Young Irish in London and Return Migrants
}

\author{
Aija Lulle, Liam Coakley and Piaras MacÉinrí
}

\begin{abstract}
We bring into dialogue the migrant identities of young Irish immigrants in the UK and young returnees in Ireland. We draw on 38 in-depth interviews (20 in the UK and 18 in Ireland), aged 20-37 at the time of interview, carried out in 2015-16. We argue that 'stretching' identities critical and reflective capabilities to interpret long histories of emigration and the neglected economic dimension need to be incorporated into conceptualising "crisis" migrants. Participants draw on networks globally, they choose migration as a temporary "stop-over" abroad, but they also rework historical Irish migrant identities in a novel way. Becoming an Irish migrant or a returnee today is enacted as a historically-grounded capability of mobility. However, structural economic constraints in Irish labour market need to be seriously considered in understanding return aspirations and realities. These findings generate relevant policy ideas in terms of relations between "crisis" migrants and the state.
\end{abstract}

\section{INTRODUCTION}

Ireland has been an emigrant economy for most of the past 200 years. Almost every generation has been impacted by the loss of people to emigration, and Ireland's sense of its place in the world has been anchored in a meta-level migrant narrative for most of its recent history. A rich and varied academic literature charts these patterns (Jackson, 1963; King, 1991; King and Shuttleworth, 1995; Miller, 1985; Walter, 2008; Gilmartin, 2015). This experience has fostered an emigrant identity informed by notions of victimhood and loss.

Irish people who emigrated during periods of economic crisis have returned to live in Ireland during periods of economic buoyancy. Whilst confined to particular periods (the decade of the 1970s, for example) significant return flows occurred in the years between 1998 and 2008 when large numbers of Irish emigrants were attracted back to live in Ireland on foot of the unprecedented range of economic opportunities then on offer in Ireland's so-called "Celtic Tiger" economy (Gilmartin and White, 2008).

In this way, national migrant identities in Ireland tend to be informed by notions of crisis and emigration, on the one hand, and opportunity and return on the other, at different times. In this paper, we propose to approach the complexity of Irish migrant identity from this standpoint. We focus on Irish youth emigration and return during and after the last economic downturn, which began in 2008. We explore the complexity of migrant identities in the context of crisis and the two-directional flows of emigration and return relevant to Ireland by building on the separate literatures that firstly explore Irish migrant identities whilst resident in locations outside the island of Ireland, and secondly upon return to Ireland. Specifically, we bring into dialogue the emigration and return experiences of young Irish under the following research questions: 
1. How do young Irish migrants and returnees reflect on historical and contemporary migrant identities? 2. How did “crisis" feature in migrants' accounts, revealing potentially novel aspects of a migrant identity?

Based on our data, we argue that the capacity to be mobile gives rise to migrant identities, where notions of victimhood and desolation are reworked into identity processes where global and national co-exist and reinforce each other. Simultaneously economic opportunity structures in Ireland are crucial, yet these are often hidden deeper under narratives of Irish migrants as now resourceful world citizens.

\section{EVOLVING MIGRANT YOUTH IDENTITIES AND CAPABILITY OF MOBILITY}

When studying mobility plans by young Irish during the economic crisis, Cairns (2014: 246) found that most of his respondents intended to leave Ireland only for a short period and wanted to go to English-speaking countries. In order to build on these findings through our data on actual migration experiences after the crisis, we seek to develop a broader theoretical context on linkages between crisis, identities and capability of mobility. To begin, we take seriously Ní Laoire's (2000) cautionary advice against the "normalization" of migration for certain cultures. We take this warning as a starting point to defining our approach to migrant identity construction and the notion of capability to move in particular.

Contemporary migrants draw upon historical tropes when making sense of their own mobilities. Equally however, we accept that these identities can be situational and contextspecific (Hall and du Gay, 1996) and images of personhood and agency underlie many evolving identity processes. Dick (2010), for example, claims that attachment to certain forms of "social personae" is relevant to how people construct their identities. This has been underlined by Ní Laoire (2008) on how life events intersect with economic events, producing certain narratives of return with emphasis on family, child-rearing and "settling down" in Ireland. In this way, our aim here is to uncover the shifting migrant identities that both historical and contemporary crisis contexts provoke. These evolving migrant identities, then allow us to investigate the specific capability to be mobile and to overcome economic crisis.

In his seminal critique of development economics, Sen (1999) argues that people, in their willingness to overcome inequalities, develop various human capabilities. However, there remains relatively little research on what might be called "mobility capability" in general (for an exception, see Wright, 2012). However, Näre (2014) provides a useful conceptual platform. In theorizing agency as capability, she emphasizes the fact that "migrant capabilities" are evolving and changing exactly through migration experiences. Migrants rely on different aspects of their agency such as gender, skills, networks, and selective interpretations of experiences by other people in similar situations. Importantly, de Haas (2014: 4) sees 'human mobility as people's capability (freedom) to choose where to live.' Building on these insights, we define Irish youth's "capability of mobility" as the ability to alternately draw upon and resist historical tropes of an Irish migrant and contemporary aspects of identities, mobilize networks and remain open to economic and emancipatory possibilities of both return and further mobility onwards to other destinations.

We will now review concisely the history of Irish migration in order to distinguish relevant tropes and contexts that inform contemporary identities and against which new identifications are forged. 


\section{EMIGRATION, RETURN MIGRATION AND CRISIS IN IRELAND}

Whilst Irish people were already emigrating in the late $18^{\text {th }}$ and early $19^{\text {th }}$ centuries, particularly large numbers of Irish people left the island in the decades succeeding the great Irish famine of the 1840s. Large-scale out-migration occurred during the famine. Due to broad networks established abroad, later movement was enabled. Since then, several very significant periods of emigration have occurred during periods of economic difficulty. Large-scale emigration took place in the decades of the 1940s, the 1950s, and the 1980s. According to Ewart (2011), it was estimated that half a million Irish people left their country due to prolonged poor economic conditions during the middle decades of the $20^{\text {th }}$ century - a substantial proportion of whom emigrated to the UK. A further half-million left in the 1980s as the Irish economy struggled to adjust to the new realities and challenges of EEC (EU) membership. According to Glynn, Kelly and MacÉinrí (2013: 10-11) net migration during the mid-20 $0^{\text {th }}$ century was approximately 500,000 but statistics is rather poor in the $1940 \mathrm{~s} / 1950 \mathrm{~s}$. Net migration during the $1980 \mathrm{~s}$ was roughly half.

Large numbers of Irish-born people emigrated from Ireland in the years following the collapse of Ireland's "Celtic Tiger" economy, between 2008 and 2016 (Glynn, Kelly and MacÉinrí, 2013: 19). Between 1998 and 2008, in tandem with flows of non-visa-required intraEU mobile citizens and visa-requiring third-country nationals, large numbers of previous Irish emigrants were attracted to live back in Ireland (Gilmartin and White, 2008). About half of the 1980s emigrant outflow returned. However, the collapse of Ireland's banking sector, a national budget deficit that was proportionately the largest in the EU in 2010, led to a massive retraction in all sectors of Ireland's labour market, and Ireland became a country of net emigration once again.

This cycle of boom and bust had a massive impact on the Irish population's "sense of self', and on Ireland's cultural register - which came, at the time, to be marked more by the experience of "austerity" than by anything else. And in the process, Ireland's national migration narrative certainly changed from a "Celtic-Tiger" discourse of immigration and integration to one of "austerity" and "forced" emigration due to severe economic retrenchment. Irish public attention turned, in particular, to the emigration of young Irish-born people. There were 389,000 people born in the Republic of Ireland residing in the UK in 2017; This made Ireland the fourth most common country of birth after Poland, India and Pakistan. Approximately 100,000 Irish together came during the crisis years (ONS, 2017).

That said, return remains part of the conversation about Irish migration. Even at the height of this recent emigration phase, Irish people were returning from abroad to live in Ireland. Glynn, Kelly and MacÉinrí (2013) suggest that a very large proportion of current Irish emigrants harbour definite plans to return to Ireland, at some point in their future lives.

\section{METHODOLOGY}


Our data derive from a large-scale Horizon 2020 project (BLINDED). ${ }^{1}$ We draw on 38 indepth interviews conducted with Irish participants, 20 of whom were interviewed in London and its metropolitan area 18 in Ireland in 2015-16. Practically all of our participants were tertiary-educated, or were pursuing higher education at the time of interview. The sample in the UK include eight students and one participant who had interrupted her studies in Ireland but hoped to transfer to the UK, and 10 high-skilled participants. All interviews were carried out in urban environments - in London or its urban surrounds. The interviews in Ireland were either carried out in the Dublin area - four high-skilled and four students; or in rural areas six high skilled and four students.

A typical interview lasted one hour, was recorded and transcribed. All interviews were carried out in English. Participants were aged 20-37 at the time of interview; genders were balanced. Pseudonyms are used throughout. Most participants were either studying or had already completed their higher education. Most were at least employed part-time in skilled and creative jobs, but some recent graduates were employed in unpaid internships, in a volunteer capacity or combining high-skilled job search with lowly-paid work, for example in the service sector.

Interviews were analysed thematically. Particular attention was paid to the following interlocking themes: i) participants' migration trajectories and motivations, ii) references to historical migration tropes and legacies, iii) reflections on current identity issues, and iv) references to existing policies. It is important to note that participants were not prompted to discuss and reflect on reworking historical identities. These themes came up in different parts of interviews as self-initiated. This methodological finding strengthens further our conceptualisation on linkages between identities and mobility capabilities.

\section{EMIGRANTS - IN LONDON 'FOR THE TIME BEING'}

These two main empirical sections contain analyses of current migrant identities in London and, secondly, current return identities in Ireland. Interviews conducted with Irish immigrants in London are used to explore how young Irish migrants ground their reflections and rework historical meanings of crisis in their current stories. This is followed by an analysis of Irish mobilities during the economic crisis. We initially concentrate on emigrants' capabilities to return, but we also draw on interviews conducted with recent returnees to Ireland to explore these capabilities further.

\section{Historical "crises" reworked}

Most interview participants reflect on historically-formed Irish migrant identities and link these to personal experiences and to a migrant ethos today. Let us begin with a long excerpt from Patrick, a 25-year-old Irish student living in London. He studied business and law in London but also worked part-time as an actor and a waiter, and engaged in several unpaid volunteering activities amongst the Irish community in the UK. He states:

[A sense of] oppressed humanity has been collectively passed down through generations. And I think it informs me today just as much as it informed anyone within 
that line. That is very much alive in me. And once I moved over here I started to really look into that. The love of kind of where I come from and the Irish culture has become a lot stronger. [...] I think you win the lottery when you are Irish. Genuinely it is the ultimate white privilege if I am being honest as well. Because essentially people are more positively predisposed towards Irish people than anyone else in the world. So we have this incredible privilege that we are born with. I don't think we necessarily deserve it. But that also makes me see it as a responsibility. And the way to our history is not just to see it in the context of ourselves but to be able to empathize with generations and cultures that are experiencing the same oppression and suffering that was the backbone of our history for hundreds of years. My Irish identity is massive, it is huge. It probably affects me more than any other part of my identity.

We note how Patrick reflects on intergenerational continuity as the most important part of his identity. However, he does not express his ethnic Irish identity as oppositional to other ethnic groups; he builds on historical legacies to expand on "white privilege" and solidarity. Patrick also emphasizes the fact that past sufferings have laid the foundations for better young Irish citizens lives today, and he underlines the individual's responsibility to acknowledge and work with this history. This leitmotif of the colonial past and encounters with indifference is further reflected in the stories of other London participants, such as Daniel, high-skilled, aged 27, who stated that colleagues 'were absolutely oblivious to the fact that Ireland was a separate country to the rest of the United Kingdom.' Such reflections came up in interviews regularly, as in the quote from Rachel, 24 years-old pubic relations specialist in London:

We got taught about independence in school, but English people have no idea about it. Just recently I was asked where I was from and I said that I was from Ireland and the person asked: 'From which?' I said that from the Republic of Ireland, but the person

asked me to tell the differences between them because he didn't have a clue.

In summing up the dynamics of historical identities, we draw on Ewart's (2011: 229) research on working-class Irish in Coventry and assert how interviewees in this research are aware of historical tropes of poverty. However, these migrants do not draw solely on these historical narrative resources to perform their migrant identities. Instead, Irish migrants presented themselves as knowledgeable of political and economic underpinnings; as exercising their agency and choice in their decision to leave Ireland (cf de Haas, 2014).

\section{The capability to move during economic crisis}

The participants do not describe the impact of economic crisis in terms of poverty and desolation. Rather, several quieter "registers" emerged, expressed by historically informed discourses on social networks in migration.

Chris, 35, has a bachelor's degree in IT. He first internally moved to study in Dublin, then moved "around the world", to Brazil, US and Spain, and arrived in London in January 2012. When asked "Why London?, he replied:

It was just for a change of scenery. And also I had a friend there as well. So for the first few months I was able to - I had accommodation which made it a lot easier. If it wasn't for that I probably couldn't have afforded to go there. 
Chris, in common with many of our participants, sees his movement to London as a temporary migration. His narrative is grounded in a youthful exploration of European cities and of world travel. Only in passing does he mention the fact that a friend facilitated this potentially expensive move through the provision of accommodation. This is a common pattern in the data. Many migrants initially share accommodation. This can often be provided by friends already resident in London. Others, like Rian, who used to work in Dublin but was studying in London at the time of the interview, emphasized the difficulties finding accommodation in Dublin. Even if jobs in IT were available in Dublin during the crisis, it was more difficult to find an affordable place to live.

Moving out of Ireland and to a bigger economy was also pragmatically justified through reflections on supra-national austerity solutions and a critique of the European Union and its policies. Cian, for example, states:

Europe for Ireland politically and economically has made a lot of demands on Ireland as they [EU] have done to a lot of smaller member nations in the wake of financial crisis. And I don't think that has been particularly helpful to economic recovery in Ireland. (Cian, student, aged 26).

Another commonly referenced "register" is the lack of opportunities for personal growth in Ireland, and the desire for a more "active" life abroad. Students who participated in the EU's Erasmus exchange programme, or young Irish who took a gap year in Australia or New Zealand, and those of our participants who went as English language teachers to Asia, Russia and Middle East, all emphasize a need to challenge themselves and discover a "wider" world. Upon return from such prolonged time abroad, Ireland was also sometimes used as a "stop over" to rethink an onward move which led participants to London. Accordingly, in order to overcome crisis, many of the participants relied on global possibilities for native or bilingual English speakers, and on friends or distant acquaintances for practical reasons.

Personal reasons were emphasized too. Among these, complicated relationships with parents, or sexual identity, impact migrant identities in complex ways. For some, emigration from Ireland is associated with a sense of freedom and possibility. Two of our participants emphasized that their sexuality was at least as important as their area of study in shaping their desire to study in the UK, while two other participants, who left Ireland as heterosexual couples, later realized that their partners wanted to move out due to constrained sexual identity "at home". Since, as Masullo (2015) has observed, migrants relay their cultural background to express themselves and their desires in a new society, young Irish sexual identities and the political climate around same-sex relationships inform decisions to move away from Ireland and return in complex ways that overlap with the recovery from economic crisis.

Individual mobility-capability can be further strengthened through a positive sense of self as Irish. However, some research participants encountered negative stereotyping. Let us consider these words of Fergus, a 34-year-old international NGO manager:

I find a significant amount of casual racism against the Irish in the City. So lots of Paddy jokes and potato jokes which I am in the third phase by now. I was in a phase where I thought it was funny. And then the second phase was being quite annoyed by it. And telling people I was being annoyed by it. And now I am in a phase where - they are not going to change. It depends on how political you come at this problem, you know. You 
could call the potato famine like - it has been called a genocide, for example. So to make a joke about that to me is like would you make a slavery joke towards a black person, right? To me it is on that level.

Ryan and Kurdi (2015: 268-269) have also recently noted that whilst the political climate between Ireland and Britain can be characterized as "cordial", professional Irish in Britain still may encounter an embedded "negative stereotyping and anti-Irish sentiment, rooted in a colonial legacy". Through their reflexivity, Irish migrants can overcome such a limiting, externally created migrant identity (McAreavey, 2017) and rework their historical and contemporary identity.

\section{Staying open to possibility of return}

Many current migrants remain open to the possibility of return. Three possible return scenarios are commonly recognised by the migrants who participated in this research.

Firstly, many of those who choose not to return to Ireland because of career reasons, continue to visit Ireland. Even in these cases, the possibility of return can be implicitly present:

I don't know if I intend to [return]. Sometimes I think yes, I definitely will ... but then the next week I'll think no, I won't go back. The conditions would be that there would have to be a job there that is good enough to take me away from London. The main thing would be if it was good for my career. (Mark, aged 27)

Clearly, jobs are crucial, they shape the definite decision to return or not. Secondly, when a return to Ireland is envisaged to take place at some point in the future, migrants can harbour a transnational wish to contribute to Irish culture from a distance, as in Patrick's words:

Would I like to return to Ireland to live? Yes. But right now absolutely not. To live in Ireland, you have to be in a place where the industry comes to you. But yeah, I would love to at some stage. It is more because I feel that I want to give something back to Irish culture. Particularly Gaelic culture. It is not specifically because of my friends and family. It is more that I would want to have a more active role in the resurgence of Gaelic and Irish culture. (Patrick, aged 25)

This tendency is well recognised in the literature. For example, Ní Laoire (2008: 37) states that "the dream of return homing desire plays an important symbolic role in the maintenance of diasporic identities and ideologies". In such instances, the capability of return is clearly constrained by lack of economic opportunities back in Ireland but capability of mobility elsewhere remains:

It could go either way. It depends on how life goes. If I had a job there and would have enough money to be able to live there. (Shauna Nora, aged 30)

Thirdly, return to "anywhere in Ireland" is envisaged as moving away from "Britain", which in our participants' words placed Northern Ireland and Scotland together as "almost home". At least two of our participants interviewed in London have already moved back to Ireland - one to Northern Ireland, while another came back to Dublin. 
The returnees who participated in this study left Ireland during Ireland's recent economic "crisis" but many of these migrations were always going to be temporary in nature. Many of the returnee participants certainly state that they always harboured a desire and capability to return. This is commonly articulated through asserting both the temporary nature of migration and an anticipated eventual transition back to "family and home" in Ireland. In this way, these identities are not being "broken" by emigration and re-made in the destination but are rather being stretched during migration and re-set once "home" again. We need to problematise these findings further. Longing to go back to family and home underpins historical identities and belonging. However, prominence and positivity of this narrative line goes hand in hand with necessity to secure jobs in Ireland. Hence, capability of mobility cannot be reduced to agency and belonging. Economic structures need to be in place too. Many returned to Ireland during the 1970s and the Celtic Tiger period due to economic opportunities back home and to be close extended families, whereas relatively few returned in the 1950s and 1960s and it is hardly imaginable that this cohort of migrants did not long to return to their homeland and be close to their families.

Some students and early-career professionals stated that they always felt that they were moving away from Ireland for a set period and that a return to their country of origin was part of their migration decision-making process (Lulle and Buzinska 2017). Danielle (age 27) offers clear evidence of such an engagement when stating that she "didn't know exactly for how long (she) was going to be gone for really but yeah I think the plan was always to come back".

These returnees have now returned to Ireland at a "natural" break in their migration either at the end of their studies or as a period of paid employment has come to an expected end - and no disruptive renegotiation of identity has had to occur. Return was narrated as a "natural" end of a migration cycle because these students intended a strictly temporary sojourn, while those who have lived in several countries, spoke about their willingness to discover a "wider" world, like some of those interviewed in London. Accordingly, the current position - being a migrant or returnee - clearly shapes the narrative and justification of migration trajectories and stretches their identities across borders.

Such a return is often still dependent on opportunities "back home." Return remains contingent on securing paid employment in Ireland, for many. Tom, 35, an engineer from Galway is illustrative of this agency-structure dichotomy when he clearly states that he "wasn't expecting to come home" until he received an offer of an attractive position in Dublin. He goes on to ground this understanding in his wider friend-group when he states:

An awful lot of people that I know are not fully convinced that it's time to come home. Yeah, because there's an awful lot of jobs like that, we went as engineers, architects, lawyers and, went over to, and got very good jobs and got very well respected, because they went over very well educated.

He finishes in a particularly illustrative manner when he states that "an awful lot of my friends now are doing very well and can see no point in coming back to a country with higher tax", for example. At this level at least, many returnees are still acting as rational economic actors. But, a range of wider influences are discernible as well, and many young Irish returnee identities are grounded in "quieter" registers of preferred life-place and lifestyle. Specifically, many individual migrants' capabilities to return are anchored in i) discourses of "home" and family, 
ii) personal growth and success achieved in the destination, and iii) the possibility of circulation or onward migration.

\section{Family, networks and the capability to return 'home'}

Discourses of Ireland, the "Irish ways of doing things", and Irish family life are commonly included in the narratives gathered here. These returnees are moving back to Ireland to be closer to their own "people" and, as in discourses of return among other national and ethnic groups, to settle down in what is deemed to be an Irish milieu (Ní Laoire, 2008).

A strong and undiluted sense of Irish identity and Ireland as "home" is voiced by many. As Claire states: "I mean it's Ireland, it's home you know". Toni is particularly illustrative of many others' perceptions in this regard, when she considers her motivation to return to Ireland and states "the main advantages - being with your family, being in my own culture". She goes on to qualify her statement by adding "I didn't realise actually until I moved to England how different we were".

Such difference from a person's host community, even when experienced against a backdrop of migratory success, can prompt a return to the country of origin. A sense of dislocation, even of a relatively benign nature, can prompt the migrant to view past lives in a positive manner (Ní Laoire, 2007). This realization can become particularly important to people who are transitioning from one stage of life to another. People contemplating starting a family constitute a common example here. As, Pamela, a 26-year-old student, states:

I kind of thought maybe that I'd like to settle in Ireland and, you know I think as a woman as well, I'm like 26 now. So can I OK, well, you know to have a family, and you know things like that, it's just you start to think about.

People who moved away from Ireland to avail of career opportunities thus come to reevaluate their needs, with time. Judy (age 33) is clear in this regard when she states that she returned "to be closer to my family; I didn't want to settle in England". Familial bonds and care-based obligations become more important with time for her. Indeed, in this excerpt, she is clear in stating that this aspect was a strong influence on her decision to return to Ireland:

I always think if my parents get older I don't want to be that far away that I can't be there to help out and support them. (...) I know that's thinking way far ahead, but that was always in the back of my mind, I wanted to be able to drive home, not book annual leave, that kind of thing. And family and friends are more important, but I wanted a good enough job that I was happy with here.

This final sentence is telling. Migrants who state that they have been successful in their migration away from Ireland do tend to cite the importance of family in their decision to return. The importance of family as a pull factor for return and remaining in the country of origin may still be contingent on getting a job that pays well enough to do so. A point echoed by Padraig, a 26 year old construction engineer, who, as part of a wider contemplation of return states that the desire to start a family was "something I didn't want and I wanted to do all that at home, you know", Of course, the importance of family as a pull factor for return and remaining in the country of origin may still be contingent on getting a job that pays well enough to do so. David, 32, a teacher who returned to Ireland after a period spent working in London is illustrative here when he relates that his decision to return was: "primarily for work but the, I think there is an 
easier lifestyle certainly than in London and we did see more of our families of course and some of our friends. A strong sequence of return is discernible. Many initially return to the place in which they grew up.

However, an initial home-bound mobility can be quickly overtaken by a dissatisfaction with the pace of life in the place of origin, especially if this location is a small town or rural location. Returnees state that their initial satisfaction in returning to their family roots comes to be tempered by an emerging dissatisfaction with the reality of daily life in a small town or village, and they soon start to seek new opportunities. Hence, a strong urban drift is evident. Dublin exerts a particularly strong draw but people move away from their family's home place to the city where their third-level studies were pursued as well. Interestingly, these onward moves are still deemed to constitute a move "home". John, a highly skilled returnee in his $30 \mathrm{~s}$ for example, who lives away from his family location, stated that "I am, I am happier at home [in his new location of Galway city], yeah definitely yeah".

Family networks remain important facilitators of such moves. Siblings living in distant parts of the country can be of help to the returnee. One migrant, Geraldine, who returned to Ireland to study, moved back to the Dublin area rather than to her place of origin in the west of Ireland because of the assistance offered by a family member living in the east of the country. This sense of return can be facilitated by the fact that many of the migrants who participated in this research have engaged in regular travel between their country of destination and their place of origin over the course of their migratory experience.

\section{'Success' abroad and the capability to return}

Participants in this study have grown through their experience of migration and have returned to Ireland with an enhanced range of skills and experiences to draw upon. Social and familial support networks are important to the returnee but, as is illustrated in this next excerpt from Judy, a healthcare worker aged 33, many returnees also draw confidence from the experiences they gained whilst resident in another country:

I've a sister here in Dublin who helped me find accommodation, so actually it went quite smoothly. It was easier moving back than when I moved over to England actually, yeah. I was sad to say bye to people, but it wasn't as big of an upheaval as when I left Galway to go to England on my own. And I guess because I've learnt so much in England, I've toughened up a bit, you know just things that wouldn't bother me as much as they did initially.

Jamie, 31, a musician, mirrors such feelings when, as part of a wider contemplation of return he states that "I'd have no fear of being somewhere else or starting a new life somewhere" as a result of the experiences he gained whilst away from Ireland. This is a common assertion. Returning migrants point to their increased ability to deal with life/work situations that arise. In this respect, migration has changed the "person" (Dick, 2010) and an increased pallet of skills and competencies is drawn upon. Returning migrants can also benefit from a ready-made support network on return - a sister, in this instance. The capability to mobilize assistance given by siblings and family members can do much to smooth any of the difficulties experienced on return, at least during the person's initial settling-in period in 
Ireland. Individual competencies gained whilst a migrant are complemented by the range of supports available via the family network back in the country of origin.

Some returnees were apprehensive at the thought of return. Angela, aged 26, a student, is illustrative of such people.

I was a little bit worried that it would be hard to move back in after being kind of independent for two years, to move back in with the family and all that. But it worked out well.

However, movement is deemed to have equipped the migrant with a range of skills (both of a formal and informal nature) that helps facilitate return to Ireland. Liz, for example, cited the increased self-awareness and understanding of how she communicates with people - skills that she developed as a migrant - as being important to her.

\section{Return in advance of onward circulation}

By and large, the return migrants in this research have completed their migration journey and were hoping to settle permanently in their country of origin. Awareness of the opportunities for onward travel was more an idea than a reality (Erin, a student, for example, referenced possible moves to Dubai) but only a very small number of the people who participated in this research harbour definite thoughts of onward circulation. ${ }^{2}$ Judy is illustrative of many when she talks of possible future moves abroad:

[I] wouldn't rule it out a hundred per cent, but I know in the back of my head it wouldn't [happen] I guess I know it's an option and I wouldn't say never, but I don't, it wouldn't be an easy thing to do, especially now that I'm back.

Some participants do harbour thoughts of further travel, often of an extended nature. Lucy (aged 27), for example, states that she would like to move away from Ireland again. However, she is clear in stating that this move away would be for a specific period of time and not an open-ended migration:

Basically I'd love to take like say a year out, a career break meaning they'd have my job for me when I came back so I wouldn't have to look again and then just travel and possibly, maybe, if I ran out of money, do agency [work] wherever I was.

There is no strong evidence to suggest that the impulse to migrate onwards remains in place after return to Ireland. Indeed, participants are generally clear in stating that they wish to remain resident in this country now that their migration journey has been completed.

\section{POLICY IMPLICATIONS}

The migrants who participated in this study had a positive sense of their Irishness. This positivity of identity increased their capability to move away from Ireland and to develop networks to stay abroad. The historically-formed migrant narratives which the current young generation have reworked, together with personal migrant experience and existing networks of family and friends abroad, amplify the capability to be globally mobile.

For example, Caitlin (a student aged 28, interviewed in the UK) contemplated life abroad between her Bachelor's and Master's studies in the UK. At the time of the interview, 
when she was finishing her Master's, she was still considering a move to another country where priority schemes for young and skilled workers were available. She states:

I am quite Irish. Because you want to still be Irish (..) even when I was living in Russia. My brother lives in Brazil, my sister lives in the Middle East. I live here. And my other sister lives in Belfast. So it's quite spread out.

And what's your next move?

God knows. Just had a brief look the other morning at moving to Canada.

"Home" can be experienced at a national level for some, whilst being a more locally experienced idea for others, and absolute distance from family does not impact on an increased sense of immediacy experienced by returnees to Ireland. In this way, returning migrants who move to live at some distance from their point of origin still categorise their return as a return "home".

Openness to the world, and a sense of a global or European belonging, co-exist with being "very proud to be Irish" (Chris, 35, interviewed in the UK). Yet, Irish people's global mobility capability needs to be interpreted carefully in policy terms, when combining resourceful national and global identities, an awareness of historical traditions of migration (Ryan, 2015b) and in situations of economic crisis (Glynn, 2015). Research participants were self-conscious of what we could call a double-privilege in a globalized world - being native English speakers and, at least in part, having a "white privilege". Furthermore, the interviewees were highly reflexive and critical of politics and policies in Ireland. Many were making a personal effort to influence change, for example by travelling back to Ireland to cast a vote on Ireland's 2015 "Marriage Equality" Referendum (O'Leary and Negra, 2016) and actively expressing views for more liberal abortion rights. Liam, 35 a teacher in London, is illustrative of many, when he explains why he was not willing to move back to Ireland, at least not immediately:

I feel broadly positive about it [Irishness] here in London. But things like, you know, the lack of options for abortions. Those kind of things are really high profile in Ireland. I think they reflect quite badly on Irish people actually.

Ireland has recently achieved legislation changes: the Health (Regulation of Termination of Pregnancy) Act 2018 was signed by the President of Ireland on $20^{\text {th }}$ December 2018.

Most importantly in terms of overcoming economic crisis, the continuity of economic and professional activities across the migration cycle would maximize opportunities also for places where they migrate or return. Returnees reference an increased confidence in their ability to succeed as well as the ability to operate in an unfamiliar environment and communicate with new people. Judy, 28, a medical professional who has recently returned from a period at work in the UK, gives a good overview of the types of commonly referenced skills and competencies when she states, of her return experience:

I would have I guess more confidence at work and communicating things. I was really shy when I first started (..) whereas now I can, like I will go on ward rounds and discuss things with consultants and junior doctors, and I'm not scared anymore or shy.

Accordingly, her capability of return in this case was amplified by her enhanced sense of personal competence and ability to be internally mobile. 
Global mobility capability is a feature of Irish people but cannot be the only corner stone of policies. On policy recommendations, there is a clear need to make an effort nationally and globally to recognise skills and personal growth achieved during migration. There is a specific need to develop more inclusive policies for young couples with different skills and national backgrounds. But in order to do so, economic dimensions cannot be overlooked as it is an "iceberg" under the positive "top" of global resourcefulness. As noted by Gray (2004: 84): 'When high levels of out-migration returned in the 1980s, this new generation of migrants was appropriated into national narratives of modernization through notions of "the global'. 3 A 'global nation' and emphasis on skills and talents smoothly entered into a policy rhetoric as an easy way to talk about emigration and return (cf Conlon, 2009). Ireland has benefited from its citizens' global mobility capability; emigration during crises eases pressure on unemployment and the social sphere. However, two-way support and social contract between the state and migrants during crises is asymmetric. the Irish policymakers need to make greater progress in granting rights of external voting and recognition of these migrants as fully global Irish citizens. Glynn, Kelly and MacÉinrí (2013: 92) research demonstrate great support for such extended rights among Irish citizens.

\section{CONCLUSIONS}

We find, firstly, that historical migrant identities provide complex tensions for the participants. They were highly reflective on the legacies of culture of exile (Miller 1985), migration, and positive about their contemporary identity as Irish migrants. But above all, the participants have reworked their migrant identities where "national" and "global" co-exist. We claim this as a crucial moral lesson for migration and return migration policies, both in the Irish case and beyond. We demonstrated throughout the paper how these important underpinnings informed young Irish participants' capabilities of mobility. However, we make the limitation and specificity of our study clear: most of the participants were high-skilled professionals or students. The cultural capital they possess increased their capabilities to "normalize" migration and hence to somewhat downplay the immediate impact of the economic crisis. Thus, more studies are needed among lower educated migrants to further contextualize or contest these findings.

Secondly, the participants "stretch" identities; they do not create their migrant identities in an oppositional manner. Young Irish mobility capabilities have a strongly global dimension. All were native English-speakers, but most particularly emphasize their Irishness as a positive difference from global English-speaking youth. In addition to what Cairns (2014) stated as an obvious willingness to migrate to English-speaking countries, we found an even broader openness to the world through globalizing identities, where English skills are relevant but only one aspect of the identity and capabilities of being mobile. Young Irish people do not solely draw on their ethnic identities but more so on other aspects, for instance, like the inter-ethnic professional identity of a teacher (Ryan 2015a: 1676 and on networks Glynn 2015).

Thirdly, there are parallels between post-2008 crisis migration and the research done by King and Shuttleworth (1995) on the graduate emigration wave of the 1980s. Part of their 
thesis was related to the general economic depression in Ireland of those years, but part of the explanation also lay in the small scale, "truncated" and peripheral nature of Ireland and its graduate labour market, which limited opportunities for those with specialized qualifications.

Besides these findings on migration trajectories due to "crisis", our qualitative study shows that nowadays migration is seen as a temporary solution for many graduates where return is one of many solutions if economic opportunities are in place, along with possible onward migration globally. Among the actual returnees, support for the idea of a permanent return was very strong. But also upon return, young people enact their capability of mobility through internal migration due to economic reasons, usually to larger cities, where they have better chances in the urban labour market. Some also stay open to future mobility elsewhere.

Finally, we invite migration scholars to re-think how the notion of "crisis" is informed by deeper historical and contemporary identity processes and how "easy" ideologies of globally resourceful migrants come into existence. Staying attentive to economic structures and social contract between states and their emigrants is vital in future research on crisis migrants. 


\section{REFERENCES}

AUTHORS

Cairns, D. 2014 “"I wouldn't stay here': economic crisis and youth mobility in Ireland”, International Migration, 52 (3): 236-249.

Conlon, D. 2009 “'Germs' in the heart of the other: Emigrant scripts, the Celtic Tiger and lived realities of return", Irish Geography, 42 (1): 101-117.

De Haas, H. 2014 Migration Theory. Quo Vadis? DEMIG project paper 24, No 100. pp. 139.

Dick, H. 2010 "No option but to go: Poetic rationalization and the discursive production of Mexican migrant identity", Language\& Communication, 30 (2): 90-108.

Ewart, H. 2011 '"Coventry Irish': community, class, culture and narrative in the formation of a migrant identity, 1940-1970", Midland History, 36 (2): 225-244.

Gilmartin, M. 2015 Ireland and Migration in the Twenty-first Century, Manchester University Press, Manchester.

Gilmartin, M. and A. White 2008 "Revisiting contemporary Irish migration: new geographies of mobility and belonging", Irish Geography, 41 (2): 143-149.

Glynn, I. 2015 “Just One of the 'PIIGS' or a European Outlier? Studying Irish Emigration

from a Comparative Perspective”, Irish Journal of Sociology, 23 (2): 93-113.

Glynn, I., T. Kelly, and P. MacÉinri 2013 Irish Emigration in an Age of Austerity: A Report on an Irish Research Council funded study of Contemporary Irish Emigration. University College Cork, Cork.

Gray, B. 2004 Women and the Irish Diaspora, Routledge, London.

Hall, S. and P. du Gay 1996 Questions of Cultural Identity, Sage, London.

Health (Regulation of Termination of Pregnancy) Act 2018 Houses of the Oireachtas Available: https://www.oireachtas.ie/en/bills/bill/2018/105/

Jackson, J. A. 1963 The Irish in Britain, Routledge and Kegan Paul, London.

King, R. ed. 1991 Contemporary Irish Migration, Geographical Society of Ireland, Special Publication No. 6, Dublin.

King, R., and I. Shuttleworth 1995 "The emigration and employment of Irish graduates: the export of high-quality labour from the periphery of Europe", European Urban and Regional Studies, 2 (1): 21-40.

Lulle, A. and L. Buzinska "Between a 'Student Abroad' and 'Being from Latvia': Inequalities of Access, Prestige, and Foreign-earned Cultural Capital", Journal of Ethnic and Migration Studies, 43 (8), 1362-1378.

Marriage Equality Referendum (2015) Thirty-fourth Amendment of the Constitution Act, 2015. Irish Statute Book. Available: http://www.irishstatutebook.ie/eli/2015/ca/34/enacted/en/html

Masullo, G. 2015 "Homosexuality elsewhere: Young migrants, sexuality and transcultural identity strategies", Academicus: International Scientific Journal, 12: 120-133. 
McAreavey, R. 2017 "Migrant identities in a new immigration destination: revealing the limitations of the 'hard working' migrant identity", Population, Space and Place, $\mathbf{2 3}$ (6): e 2044.

Miller, K. A. 1985 Emigrants and exiles, Oxford: Oxford University Press

Näre, L. 2014 "Agency as capabilities: Ukrainian women's narratives of social change and mobility", Women's Studies International Forum, 47: 223-231.

Ní Laoire, C. 2000 "Conceptualising Irish rural youth migration: a biographical approach", International Journal of Population Geography, 6 (3): 229-243.

Ní Laoire, C. 2007 “The green green grass of home? Return migration to rural Ireland”, Journal of Rural Studies, 23 (3): 332-344.

Ní Laoire, C. 2008 "Complicating Host-Newcomer dualisms: Irish return migrants as homecomers or new-comers? Translocations: Migration and Social Change, 4 (1): 35-50.

O'Leary, E., and D. Negra 2016 "Emigration, return migration and surprise homecomings in post-Celtic Tiger Ireland”, Irish Studies Review, 24 (2): 1-15.

ONS 2017 Table 1.3. The Overseas born population in the United Kingdom, January to December $2016 . \quad$ Available: https://www.ons.gov.uk/peoplepopulationandcommunity/populationandmigration/int ernationalmigration/datasets/populationoftheunitedkingdombycountryofbirthandnatio nality [accessed 22.12.2017]

Ryan, L. 2015a "Friendship-making: exploring network formations through the narratives of Irish highly qualified migrants in Britain", Journal of Ethnic and Migration Studies, 41 (10): 1664-1683.

Ryan, L. 2015b “"It's Different Now': A Narrative Analysis of Recent Irish Migrants Making Sense of Migration and Comparing Themselves with Previous Waves of Migrants", Irish Journal of Sociology, 23(2): 114-132.

Ryan, L., and E. Kurdi 2015 “"Always up for the craic': Young Irish professional migrants narrating ambiguous positioning in contemporary Britain”, Social Identities, 21 (3): 116.

Sen, A. 1999 Development as Freedom. Oxford University Press.

Walter, B. 2008 "From 'flood' to 'trickle': Irish migration to Britain 1987-2006", Irish Geography, 41 (2): 181-194.

Wright, K. 2012 International Migration, Development and Human Wellbeing, Palgrave Macmillan, Basingstoke.

\footnotetext{
${ }^{1}$ BLINDED

${ }^{2}$ Of course, there is a source of possible bias inherent in this statement, since onward migrants who have already left are not there in Ireland (or the UK) to be interviewed.
}

\footnotetext{
${ }^{3}$ We are indebted to an anonymous reviewer for very generous suggestions on sources and critique of our earlier interpretations here and elsewhere in the text.
} 